\section{Uso variável de nós e a gente em jornais publicados na Cidade de Goiás}

\author{
Variable use of nós and a gente \\ in newspapers published in \\ Goiás City
}

Luciana Cristina de Sousa RIBEIRO (UEG) lucianacsribeiro@gmail.com Marília Silva VIEIRA (UEG) vieirasmarilia@gmail.com

Recebido em: 29 de jan. de 2019. Aceito em: 21 de jun. de 2019.
RIBEIRO, Luciana Cristina de Sousa; VIEIRA, Marília Silva. Uso variável de nós e a gente em jornais publicados na Cidade de Goiás. Entrepalavras, Fortaleza, v. 9, n. 3, p. 96-114, setdez/2019.

Resumo: As pesquisas sociolinguísticas (LOPES, 1998, 2003a, 2003b, 2004, 2007 e outras) têm demonstrado que a forma pronominal a gente está implementada no Português Brasileiro (doravante $\mathrm{PB}$ ), figurando como alternativa ao pronome nós. Ao tratar dessa temática, o presente artigo apresenta parte de uma pesquisa mais ampla acerca da variação dos pronomes-sujeito nós e a gente em um corpus escrito da Cidade de Goiás-GO. Para esta pesquisa, julgouse pertinente investigar quando a forma pronominal inovadora começou a ser utilizada pelos vilaboenses (gentílico aos nativos da cidade). Para tanto, optouse por realizar busca de textos antigos na cidade, publicados em jornais e periódicos, desde a sua fundação, até meados da transferência da capital para Goiânia. Dessa maneira, observados os períodos, almeja-se ainda verificar em quais gêneros textuais a forma esteve mais presente e se a variante nós era mais recorrente. A pesquisa está calcada nos estudos da Teoria Variacionista de base laboviana (LABOV, 1978, 2008; WEINER; LABOV, 1983; WEINREICH; LABOV; HERZOG, 2006) e nas pesquisas sobre gramaticalização clássica, a fim de investigar a variação pronominal de 
primeira pessoa do plural no Português Brasileiro (CASTILHO, 1997, 2016; LOPES, 1998, 2003a, 2003b, 2004; VIANNA; LOPES, 2015, dentre outros), A análise dos dados aponta para ocorrências da forma a gente (figurando como pronome-sujeito substituto de nós) nos anos 1800, na comunidade vilaboense, em contextos menos formais. Por outro lado, a forma nós prevalece nos contextos mais formais.

Palavras-chave: Variação pronominal. Gramaticalização. Sociolinguística Variacionista.

Abstract: The sociolinguistic studies (LOPES, 1998, 2003a, 2003b, 2004, 2007 among others) have shown that the pronominal form a gente is implemented in Brazilian Portuguese (henceforth $\mathrm{PB}$ ), appearing as an alternative to the pronoun nós. In dealing with this subject, the present article presents part of a broader research on the variation of the subject pronouns a gente and nós in a written corpus of the City of Goiás-GO. For this research, it was considered pertinent to investigate when the innovative pronominal form began to be used by the vilaboenses (gentilic adjective to the natives of the city). For doing so, it was decided to search for old texts in the city, published in newspapers and periodicals, from its foundation until meantime of the capital transference to Goiânia. In this way, observing the periods, it is still desired to verify in which textual genres the form was more used and if the variant nós was more recurrent. The research focuses on the studies of Labovian-based Variation Theory (LABOV, 2008; WEINREICH; LABOV; HERZOG, 2006) and the classical grammaticalization theories in order to investigate first-person plural pronominal variation in Brazilian Portuguese (CASTILHO, 1997, 2016; LOPES, 1998, 2003a, 2003b, 2004; VIANNA; LOPES, 2015, among others). The analysis of the data points out to occurrences of a gente (appearing as a substitute of the subject nós) in the 1800's, in the vilaboense community, in less formal contexts, while the form nós prevaisl in more formal contexts.

Keywords: Pronominal variation. Grammaticalization. Sociolinguistic Variation.

\section{Considerações iniciais}

Este trabalho pretende verificar o uso da forma pronominal a gente a partir da observação de jornais e periódicos antigos publicados na Cidade de Goiás.

Seguindo essa orientação, recorreu-se a textos antigos para observar a inserção do uso de a gente, na posição de sujeito, na então capital do estado de Goiás.

Para compor o banco de dados dessa análise, buscas foram realizadas nos arquivos da Fundação Cultural Frei Simão Dorvi e do Museu das Bandeiras (MuBan), ambos possuem documentos da época da fundação da Cidade de Goiás, onde estão localizados, além de busca na Hemeroteca Digital Brasileira, na internet.

Quanto à análise, está subsidiada nos estudos da Teoria Variacionista de base Laboviana (LABOV, 2008; WEINREICH; LABOV; HERZOG, 2006) e da gramaticalização, inserção e variação pronominal de primeira pessoa do plural no Português Brasileiro (CASTILHO, 1997, 2016; LOPES, 1998, 2003a, 2003b, 2004; VIANNA; LOPES, 2015, dentre outros). 
v. 9 (3) 96-114 set-dez 2019

No português falado no Brasil, conforme Ilari e Basso (2017, p. 176), "a conjugação verbal reduziu-se, é verdade, a duas formas: eu $\rightarrow$ falo; você, ele/ela, nós/a gente, vocês, eles/elas $\rightarrow$ fala."

Castilho (2016, p. 477) explica que os pronomes pessoais estão suscetíveis a mudanças e apresenta um quadro acerca da reorganização do quadro pronominal atual do Português Brasileiro, considerando a influência da modalidade falada, que tem impactado a estrutura sintática da língua.

Quadro 1 - Pronomes Pessoais do PB - Castilho (2016)

\begin{tabular}{|c|c|c|c|c|}
\hline \multirow[t]{2}{*}{ PESSOA } & \multicolumn{2}{|c|}{ PB FORMAL } & \multicolumn{2}{|c|}{ PB INFORMAL } \\
\hline & Sujeito & Complemento & Sujeito & Complemento \\
\hline $1^{\mathrm{a}}$ pessoa sg. & $E u$ & $\begin{array}{l}\text { me, mim, } \\
\text { comigo }\end{array}$ & eu, a gente & $\begin{array}{l}\text { eu, me, mim, } \\
\text { Prep + eu, mim }\end{array}$ \\
\hline $2^{\mathrm{a}}$ pessoa sg. & $\begin{array}{l}\text { tu, você, o } \\
\text { senhor, a } \\
\text { senhora }\end{array}$ & $\begin{array}{l}\text { te, ti, contigo, } \\
\text { Prep + o senhor, } \\
\text { com a senhora }\end{array}$ & você/ocê/tu & $\begin{array}{l}\text { vocêlocêlcê, te, } \\
\text { ti, Prep + vocêl } \\
\text { ocê }(=\text { docê, } \\
\text { cocêe }\end{array}$ \\
\hline $3^{\mathrm{a}}$ pessoa sg. & ele, ela & $\begin{array}{l}\text { o/a, lhe, se, si, } \\
\text { consigo }\end{array}$ & ele/ei, ela & $\begin{array}{l}\text { ele, ela, lhe, } \\
\text { Prep + ele, ela }\end{array}$ \\
\hline $1^{\mathrm{a}}$ pessoa $\mathrm{pl}$. & Nós & nós, conosco & a gente & $\begin{array}{l}\text { a gente Prep + } \\
\text { a gente }\end{array}$ \\
\hline $2^{\mathrm{a}}$ pessoa $\mathrm{pl}$ & $\begin{array}{l}\text { vós, os senhores, } \\
\text { as senhoras }\end{array}$ & $\begin{array}{l}\text { vos, convosco, } \\
\text { Prep + os } \\
\text { senhores, as } \\
\text { senhoras }\end{array}$ & vocês/ocês/cês & $\begin{array}{l}\text { vocês/ocês/cês, } \\
\text { Prep + vocês/ } \\
\text { ocês }\end{array}$ \\
\hline $3^{\mathrm{a}}$ pessoa $\mathrm{pl}$ & eles, elas & $\begin{array}{l}\text { os/as, lhes, se, si, } \\
\text { consigo }\end{array}$ & eles/eis, elas & $\begin{array}{l}\text { eles/eis, elas, } \\
\text { Prep + eles, eis, } \\
\text { elas }\end{array}$ \\
\hline
\end{tabular}

Fonte: Reprodução do Quadro 11.3, CASTILHO, 2016, p. 477.

Conforme exposto no quadro de pronomes pessoais, a forma a gente está, de fato, inserida no sistema pronominal, na perspectiva informal da língua, concorrendo com a forma padrão nós, mas também com eu (CASTILHO, 2016, p. 478).

Diferenças discursivas têm sido apontadas na seleção de uma ou de outra forma: nas sentenças que funcionam como figura* das narrativas, isto é, em seu nó dramático central, predomina nós; nas sentenças de fundo* (= atividades, comportamento, costumes, opiniões e generalizações), predomina a gente. (CASTILHO, 2016, p. 478, [grifos do autor]). 
Nessa perspectiva, Castilho (2016) elucida que, no caso do plural, a presença do locutor fica menos evidenciada (mais discreta) enquanto na forma singular a inserção fica mais evidente.

Paiva e Duarte (2006), relembrando a herança dos estudos empíricos de Weinreich, Labov e Herzog (2006), pontuam que, no caso de uma tradição literária como é a brasileira, a língua escrita se sobrepõe como uma espécie de lei que regulamenta o modelo a ser seguido. Contudo, as autoras explicam que as diversas variedades dos falares brasileiros estão mais ou menos distantes desse "modelo" imposto e que quanto mais distante dele é maior a possibilidade que estas sejam avaliadas negativamente.

Assim como Castilho (2016), Vianna e Lopes (2015, p. 130) esclarecem que "o processo de substituição de 'nós' por 'a gente' no PB se encontra em avançado estágio, na língua oral. No Brasil, tal fenômeno é amplamente caracterizado como mudança linguística."

Vianna e Lopes (2015) realizaram um panorama dos últimos trinta anos acerca das pesquisas sobre as formas pronominais, confirmando, assim, a inserção de a gente em todas as faixas etárias e níveis de escolaridade.

A variação pronominal de primeira pessoa do plural é tema de várias pesquisas no âmbito do Português Brasileiro (PB), dentre as quais destacam-se Álban e Freitas (1991), Lopes (1998, 2003a, 2003b, 2004, 2007), Vianna e Lopes (2012, 2015), entre outras.

Segundo o estudo de Omena (1978 apud Castilho, 2016, p. 478) as formas variantes nós e a gente "ocorrem com frequência maior na posição de sujeito, mas a substituição por nós é mais acentuada na função de adjunto adverbial".

A forma a gente é favorecida principalmente em contextos em que a referência do sujeito compreende um número grande e indeterminado de pessoas, seguindo-se o contexto em que a referência de primeira pessoa compreende um número intermediário e indeterminado de referentes. (PAIVA; DUARTE, 2006, p. 137 [grifos das autoras]).

Sobre a variação das formas nós e a gente na função de sujeito, conforme as pesquisas de Omena e Lopes (apud PAIVA; DUARTE, 2006, p. 137) "tanto aspectos morfológicos como semânticos estão imbricados na alternância entre as duas formas de referência à primeira pessoa do plural".

Nesse contexto, cabe mencionar a discussão acerca do valor de verdade (ou valor referencial), a partir dos estudos de Labov (1978, 
V. 9 (3) 96-114 set-dez 2019

2008), Weiner e Labov (1983) e Lavandera (1984). Os autores citados levantam aspectos que devem ser considerados durante a identificação se, de fato, as variantes cumprem os requisitos para serem colocadas com o mesmo valor de verdade. O próprio Labov (1978) argumenta que, sendo a variação no nível sintático, é necessário que se observem atentamente os diversos contextos possíveis em que as variantes podem se "expandir", dessa forma, sendo consideradas com o mesmo valor referencial ou não.

No que tange à variação de primeira pessoa do plural, como se trata de um fenômeno morfossintático, é primordial que todos os contextos sejam observados, a fim de garantir se as variantes cumprem os requisitos para serem consideradas com o mesmo valor referencial:

(1) A gente foi ao supermercado comprar o que faltava para a festa, meu marido e eu.

(2) Eu e meu irmão, nós buscamos o gelo para as bebidas. ${ }^{1}$

Em (1) e (2) as formas parecem cumprir os requisitos para serem consideradas, dentro do contexto, variantes com o mesmo significado e valor de verdade. Em ambos os exemplos, o referente pronominal inclui [eu + ele $]$ = nós/a gente, de fato podendo ser substituídos por uma forma ou outra sem perder a ideia central.

\section{O processo de gramaticalização da forma pronominal a gente}

Assim como ocorre com as várias pesquisas acerca da variação das formas nós e a gente, o processo de gramaticalização do item foi deveras estudado.

De acordo com Gonçalves; Lima-Hernandes; Casseb-Galvão (2007, p. 16), a gramaticalização inicia-sea partir de quando uma unidade linguística passa a "adquirir propriedades de formas gramaticais ou, se já possui estatuto gramatical, tem sua gramaticalidade ampliada". Castilho (2016) explica que a:

[...] gramaticalização é habitualmente definida como um conjunto de processos por que passa uma palavra, durante as quais (i) ela ganha novas propriedades sintáticas, morfológicas, fonológicas e semânticas; (ii) transforma-se numa forma presa; (iii) e pode até mesmo desaparecer, como consequência de uma cristalização extrema. [...]. (CASTILHO, 2016, p. 138).

${ }^{1}$ Exemplos nossos em (1) e (2). 
No caso em questão, a forma a gente deriva do substantivo gente. A origem do substantivo gente, segundo Lopes (2003a, p. 9, grifos da autora), dá-se a partir do também "substantivo latino gĕns, gĕntis: 'raça', 'família', 'tribo', 'o povo de um país, comarca ou cidade' ". Lopes (2004, p. 50) ainda explica que a forma gramaticalizada tornou-se parte de uma outra categoria/classe, ao assumir em contextos diversos determinados valores, funções e propriedades.

Quanto ao processo de gramaticalização de a gente, Lopes (2004) afirma que nem todas as propriedades do substantivo gente foram perdidas.

Na gramaticalização de gente (nome) > a gente (pronome)
ocorre o mesmo. Nem todas as propriedades formais do nome
gente foram perdidas, assim como não foram assumidas todas
as propriedades intrínsecas aos pronomes pessoais. A forma
gramaticalizada mantém do nome gente o traço formal de $3^{\text {a }}$
pessoa, embora acione uma interpretação semântico-discursiva
de $1^{a}$ pessoa [+ EU]. Mesmo que o verbo em concordância com
a gente permaneça na $3^{a}$ pessoa do singular, se pressupõe a
existência de "falante + alguém", numa frase do tipo a gente
precisa comprar a nossa própria casa. (LOPES, 2004, p. 52 , grifos
da autora).

De acordo com Lopes (2003a, p. 9), há registros da forma substantiva no singular e plural nos textos pesquisados no período do século XIII a XV e somente a partir do século XVI a forma plural caiu em desuso e a forma singular tornou-se mais utilizada.

A mesma autora (2003a) ainda explica que, herdar "o caráter genérico e globalizante" do substantivo gente, foi crucial para que várias pesquisas fossem realizadas visando investigar a possibilidade de indeterminação do sujeito. Entretanto, a essa altura do processo de inserção da forma a gente, não há que se considerar a forma como pronome indefinido e sim como pronome pessoal, como ela própria demonstra (2003a) em: "GENTE [NOME GENÉRICO] $\rightarrow$ A GENTE [PRONOME INDEFINIDO] $\rightarrow$ A GENTE [PRONOME PESSOAL]". (p. 11).

Os estudos realizados anteriormente por Omena e Braga (1996 apud Lopes, 2003a) revelam o processo de gramaticalização, sob o viés funcionalista, a partir dos estudos de Hopper (1991), descritos sob os seguintes princípios: "layering, divergência, especialização, persistência e decategorização" (LOPES, 2003a, p. 12).

Conforme o referido estudo, explica-se que a forma a gente ainda não completou seu processo de gramaticalização, considerando que, de acordo com os cinco princípios propostos por Hopper, 
V. 9 (3) 96-114 set-dez 2019

respectivamente: layering - ainda concorrem as duas formas no português do Brasil, já que tanto nós como a gente são utilizados pelos falantes de acordo com suas escolhas; quanto à divergência, a essência lexical do substantivo gente persiste na forma cristalizada a gente; com referência à especialização, "refere-se à limitação das opções que caracterizam a construção gramatical emergente, podendo chegar a um estágio de obrigatoriedade em certos contextos" (LOPES, 2003a); a persistência está fundada na conservação dos traços semânticos do substantivo gente já na forma pronominalizada (indeterminação); e quanto à decategorização, segundo apontaram Omena e Braga (1996, p. 81 apud Lopes 2003a, p. 12-13), no processo de gramaticalização, as formas "tendem a perder ou neutralizar os marcadores morfológicos e os privilégios sintáticos característicos das categorias plenas e assumir os atributos das categorias secundárias", o que ocorre com a gente.

\section{Ocorrências da forma a gente em textos antigos da cidade de Goiás: mais algumas explicações}

A escolha por estudar o fenômeno na cidade dá-se por todo o seu contexto histórico e cultural. A Cidade de Goiás foi considerada Patrimônio Histórico e Cultural da Humanidade em 2001, pela Unesco, pela preservação de seu conjunto arquitetônico. Em sua história carrega a passagem dos Bandeirantes, uma parte da escravização de negros e indígenas e ainda o título de capital do estado e Província do Brasil, tendo sido primeiro vinculada à Coroa Portuguesa e depois ao Império Brasileiro.

Após as buscas tanto nos arquivos da Cidade de Goiás quanto na Hemeroteca Digital Brasileira, foi possível identificar ocorrências da forma pronominal a gente, na posição de sujeito, nos textos antigos publicados desde a instalação da imprensa na cidade até meados da transferência da capital para Goiânia.

A maioria das ocorrências da forma inovadora foram encontradas em jornais de circulação na antiga capital, disponíveis no acervo da Hemeroteca Digital. Nessas pesquisas, foi possível observar que a expressão pronominal a gente foi pouco explorada nos textos. A expressão por ser prototipicamente mais comum na fala do que na escrita, ocorre com maior frequência em textos poéticos, crônicas, relatos e cartas de leitores. 
Julga-se pertinente explicar que, em virtude do grande acervo disponível na Hemeroteca Digital, não foi possível catalogar todas as ocorrências. Em virtude disso, foram delimitados alguns excertos para exemplificar as ocorrências de uso das variantes no dado período.

A partir do ano 1830, iniciou-se a publicação de periódicos em Goiás (estado) com a fundação do primeiro jornal (e o $4^{\circ}$ do Brasil), A Matutina Meiapontense, com sede em Pirenópolis-GO2. Na Cidade de Goiás, foi fundado o Correio Official de Goyaz no ano de 1837. A partir de então, outros periódicos tiveram circulação na cidade, com formas e assuntos diversos, passando pelas notícias, artigos de opinião, tradução de folhetins, propagandas e outros.

Durante as buscas, verificaram-se ocorrências da expressão a gente não somente na forma pronominal, assim como explica Lopes (2003a, p. 59) "porque o substantivo, antes de se "cristalizar" como a gente pronominal, ocorria precedido, ou não, de artigo definido". Nesse caso, a mesma autora (2003a) pontua, ainda, que, para identificar a forma pronominal ou substantivo, é necessário analisar o grupo de fatores "interpretação semântica".

Como exemplo, o excerto abaixo referencia a gente na interpretação semântica de (um grupo de) pessoas. No trecho, a gente civilizada contrapõe-se ao povo indígena então colonizado.

(3) E nossa sociedade existem muitas idéas falsas a respeito dos nossos autochthones, nascidas de narrações inaceitáveis e observações superficialmente feitas sobre os indígenas, não domesticados, mas desmoralizados e embrutecidos em alguns aldeamentos, onde a gente civilisada introduziu somente os seos vicios. A colonização indigena é um dos mais importantes assumptos que estão a desafiar a attenção do governo.(Trecho extraído do Jornal Corrreio Official de Goyaz, 1880, grifos nossos).

Em outro trecho, encontrou-se ocorrência que parece ser da transição da forma nominal para a pronominalizada. O excerto é parte de um texto escrito por um Cardeal na Revista A Cruz, numa edição de 1890, em que faz referência a uma figura feminina, com um relato em terceira pessoa.

${ }^{2}$ As informações quanto à instalação da imprensa na Cidade de Goiás foram possíveis a partir do levantamento feito pela pesquisadora Sra. Milena Tavares, do Museu das Bandeiras. 
v. 9 (3) 96-114 set-dez 2019

\section{(4) A MORTE DA DEUSA RAZÃO}

Nos enganamos quando dizemos no numero 27 da Cruz que vivia ainda entre nos a famosa deusa razão. Eis a relação authentica da sua morte qual deparamol-a na União Catholica de S. Paulo.

Ha de haver vinte anos vio-se um dia, n'uma obscura aldeia da França, aparecer uma mulher pela ultima vez.

Seu aspecto parecia dos mais tristes. Ella vinha coberta de andrajos, caminhava penosamente, cambaleava de quando em quando, curvada sob o peso dos anos; depois ella parava apoiando-se a um pequeno bordão, e respirava. Mas o que havia mais triste naquella mulher era o semblante ou antes o coração.

Magra, desdentada, as faces cavadas, o olhar apagado como a pouca vida que lhe restava, dil-a-heis uma idiota: ao vel-a, a gente se sentia tomada de uma immensa comiseração por aquella miserável creatura. [...] (A Cruz: Revista Catholica, 1890, p. 238, grifos nossos).

No excerto, a gente faz menção a um grupo de pessoas genérico, considerando que não é possível estabelecer a quem se refere especificamente. Desse modo, encaixa-se, dentro do contexto, na forma de pronome indefinido e não como substituto de nós.

Acerca disso, Neves (2012, p. 25) explicita que "a expressão a gente tem um uso neutro e bem tradicional em que gente é um substantivo coletivo referente a pessoas. A concordância é, como em casos do mesmo tipo, na terceira pessoa do singular e no feminino." Assim, na ocorrência, explica-se esse uso a partir da concordância verbal de a gente com tomada.

Dentro dos contextos de uso (3) e (4), não é possível substituir a gente por nós sem que seja perdido o sentido original dos trechos, já que, em ambos os casos, a forma inovadora está especificamente vinculada à carga semântica do substantivo gente em sua essência [= povo, grupo de pessoas]. Cabe citar uma outra ocorrência extraída em Freire (2006). O trecho (5) trata-se de um escrito da poetisa vilaboense Cora Coralina, então publicado no Jornal A Rosa, em 1907:

(5) [...] Meninas, não aceitavam delas senão a linguagem corriqueira e vulgar da casa. Palavrinha diferente, 
apanhada no almanaque ou trazida de fora, logo a pecha de sabichona, dona gramática, pernóstica, exibida. Um dia fui massacrada por ter falado lilás em vez de roxo claro.

E a gente recolhia a pequena amostragem, melhora assimilada de vagas leituras de calendário, folhinha Garniê e se enquadrava no bastardo doméstico.

A gente era vigiada, tinha uns preconceitos arrogantes de ridicularizar e limitar jovens personalidades, as pencas de chaves ali enganchadas nos cós das saias. (CORALINA, 1907, Normas de Educação, Jornal A Rosa, apud FREIRE, 2006, p. 50, grifos nossos).

No excerto (5), ambas as ocorrências de a gente podem ser substituídas por nós. Nesse caso, o verbo é flexionado de modo a concordar com o pronome, desse modo: "e nós recolhíamos a pequena amostragem" e "nós éramos vigiadas". Não que não caiba a concordância verbal em terceira pessoa do singular (nós recolhia, nós era), contudo, a poetisa utilizou a escrita formal, por isso, a flexão do verbo em primeira pessoa do plural.

A expressão a gente também é usada como um pronome pessoal de plural, numa referência que inclui a primeira pessoa ('nós'). [...] segundo as lições normativas a concordância com a gente (expressão que tem um núcleo feminino) deve ser feita no feminino, não importando que o faltante incluído no nós seja homem. (NEVES, 2012, p. 25, grifos da autora).

No trecho da poetisa Cora Coralina, percebe-se a necessidade de além de se incluir no grupo de a gente, incluir as outras meninas/ mulheres [eu + elas], que da mesma forma sofriam com os desmandos da sociedade patriarcal. O referente específico é percebido no contexto. No caso desse referente, o enunciador remete-se a alguma situação então vivida por ele e também por outras pessoas, que em alguns casos, não estão especificadas, mas que são identificadas no contexto.

No trecho acima, o poema de Cora Coralina, falando acerca das normas de educação. A poetisa faz uso da expressão a gente, incluindose dentro da perspectiva [Eu + outras], explicando como as mulheres, contexto em que se inseria, eram educadas nessa sociedade patriarcal. A expressão é marcada por gênero em "A gente era vigiada". Nesse caso, embora a forma a gente não seja, morfologicamente, um pronome indefinido, como no exemplo (4), a concordância nominal no feminino 
V. 9 (3) 96-114 set-dez 2019 ocorre porque o sujeito é um grupo de mulheres. Logo, se a gente é um pronome pessoal, é possível substituir a ocorrência por nós, sem perda do sentido original.

Já em (6) e (7), abaixo, a forma a gente reporta-se um referente específico, quando quem enuncia posiciona-se mais diretamente ao outro, considerando o contexto em que se coloca. Nesse caso, o pronome assume a caraterística de $1^{\mathrm{a}}$ pessoa $[+\mathrm{eu}]$.

(6) [...] Desejaríamos reproduzir todos os artigos aqui, porque, quando a gente argumenta com uma mentalidade com a do sr. Júlio, deve-se começar por soletrar-lhe o a, b, c; depois o b a, ba; o a-i, ai; o b-a-m etc... para depois passar adiante. [...] (Jornal Goyaz, 1885, p. 2, grifo nosso).

\section{(7) A' um senhor liberal}

Si ficou mal servidor com o meu procedimento resigne-se, já votei no seu partido muitas vezes; as situações políticas são tão prolongadas que dão tempo para se operar grandes mudanças... é de máo calculo ficar a gente soffrendo tanto tempo só e só para ter o gosto de votar n'om-cês... [...] Um eleitor. (Jornal O Publicador Goyano, 1886, p. 4, grifos nossos).

Nos trechos abaixo (8) e (9), extraídos de um periódico intitulado Voz do Povo, já se percebe um referente impessoal. Nesse caso, talvez de maneira proposital, a gente seja colocada numa perspectiva a não detectar um enunciador precisamente.

Segundo os estudos de Lopes (2003a), a leitura impessoal é um pouco mais complexa de se definir do que o referente genérico. Nesse caso, a gente pode ser substituída pelo clítico - se. Nos trechos com a utilização do a gente poderia se reescrever, utilizando - se. Dessa maneira, as formas ficariam assim: "o mais engraçado, compadre, é quando se leva papéis para o presidente despachar nas horas do jogo" e "e quando fala-se a respeito essas coisas, vai para a cadeia".

\section{(8) MATUTADAS}

[...] I o mais ingraçado cumpadre é condi a gente leva papé pru prisdente dispachá nas hora do jogo.

Eli fica ingirizado furibandêsco e introcha cada nomi na genti qui num tem como virá nos pe avexado e cos papé sem dispacho. Zé Matuto (Voz do Povo, 1927, p. 4, grifo nosso). 


\section{(9) MATUTADAS}

[...] é isso qui sô Totó chama de porguésso, quando nossos fio embrutece nus mato pru farta de iscola rurá i nossos animá iscadéra pru farta de caminho pras nossas casa, pruquê eles só faz caminho é prus rios de pésca e pras fazenda dellis.

E condi a gente fala a respectivo essas coisa, vae pra cadeia. (Voz do Povo, 1927, p. 4, grifo nosso).

Nos exemplos (8) e (9), pode-se dizer que as variantes pronominais não cumprem os requisitos do mesmo valor de verdade, já que o caráter generalizado de a gente predomina no contexto e, ao que parece, essa é a intenção do autor. Se substituído por nós, o contexto de determinação do referente do sujeito não seria tão impessoal quanto está descrito com a gente.

Em (10), (11), (12), (13), observa-se que são textos em que se retratam os históricos de luta do povo. O referente genérico, mas que engloba as pessoas da convivência do enunciador e na qual o mesmo se inclui, é possível de ser identificado a partir do contexto.

(10) [...] E a gente tem vontade de lutar. Vontade doida de vencer, de se sacrificar, de se lançar à grande obra de reerguimento da raça, como taboa mínima de salvação no desespero ingente do momento. [...] (ARTIAGA, 1932, p. 3 apud FREIRE, 2006, p. 151, grifo nosso).

(11) Quando se está abeirando do tumulo, é forçoso um severo exame de consciência a fazer um testamento publico para não se sucitarem duvidas, no futuro, e dar motivos á discussões acadêmicas, sobre cousas que a gente não deixou e que os herdeiros da trigésima geração disputam como herança preumptiva. (Passado! Presente... Futuro?, Voz do Povo, 1934, grifo nosso).

(12) [...] É triste a gente pensar que a morte é a única finalidade definitiva da vida. A lei máxima devia abraçar somente a alma dos máos, apagando apenas as existências póstas ao serviço das incompreensões. [...] (Trecho Obrigada, meu Deus! Jornal Cidade de Goiaz, 1940, p. 1, grifo nosso). 
v. 9 (3) 96-114 set-dez 2019

\section{(13) A REVOLUÇÃO}

Estes versos simples e belos foram escritos por um velho camponês residente em Goiás. [...]

Oh Virgem pura!/Oh que penúria!/Esta exploração./A gente não aguenta,/Com isto arrebenta/Uma grande:/ REVOLUÇÃO!/Ela é certa,/ É porta aberta./É a nossa/ INSPIRAÇÃO! [...] (O Estado de Goiaz, 1955, grifos nossos).

Nos trechos supracitados, a gente pode ser substituído por nós sem interferir no sentido original, bastando apenas que o verbo seja flexionado de modo a concordar, como no exemplo: "E nós temos vontade de lutar."; "[...] e dar motivos á discussões acadêmicas, sobre cousas que nós não deixamos [...]"; "É triste nós pensarmos que a morte é a finalidade definitiva da vida."; e "Nós não aguentamos, com isto arrebentamos uma grande revolução."

Como se observa nos trechos expostos acima, as ocorrências de a gente, tanto na forma nominal quanto na figura substituta de nós, aparecem em textos de cunho menos formal, de caráter mais poético, outrora reprodução de discursos e cartas direcionadas às críticas ao governo e até inseridas num texto de cunho irônico-satírico, como ocorre nos trechos de Matutadas, por exemplo.

Assim, como o presente trabalho trata do fenômeno de variação entre nós e a gente, julgou-se pertinente também apresentar algumas ocorrências da forma mais conservadora (nós), a partir das buscas realizadas.

Dessa maneira, verifica-se que a forma pronominal nós está sempre inserida nos contextos de uso mais formais, como atestam as ocorrências encontradas nos textos pesquisados da antiga capital goiana.

O excerto abaixo foi extraído de um discurso então proferido na Câmara Temporária, datado de 8 de agosto de 1885, pelo Senhor Leopoldo de Bulhões.

(14) [...] O Sr. Leopoldo de Bulhões: -Nós, para conseguirmos estas duas ideias, gastamos 14 annos! A libertação dos sexagenários foi votada pelas côrtes hespanholas em 1870, na mesma ocasião que se libertava o ventre. Dez annos depois, em 1880, a Hespanha votou a abolição immediata impondo condição de serviços, com praso mais ou menos longo, conforme a idade dos libertos que se denominaram-apatrocinados. 
[...] Ora, tendo nós abolido o tráfico em 1831 nominalmente, e realmente em 1850, tendo em 871 votado um plano de emancipação gradual, que já produziu todos os seus effeitos, todas as suas consequências, agora só nos resta votar uma medida radical. [...] (Trecho extraído do Jornal GOYAZ: Órgão do Partido Liberal, 1885, p. 4, grifos nossos).

A referência de nós em (14) insere o enunciador no contexto [eu + vocês], já que, ao parece, fala aos demais colegas da Câmara que participaram/estão inclusos no processo de libertação de negros escravizados. O uso do pronome nós tem referente específico, já que é possível retomar no contexto a quem se refere de maneira bastante clara.

O excerto (14) apresenta duas ocorrências do pronome nós. Em ambas, não haveria prejuízo de sentido original se se substituí-lo por a gente. Por conta de todo o contexto sócio-histórico, político e cultural da época, talvez a substituição da variante padrão pela inovadora pudesse não ter a mesma aceitação como acontece nos dias atuais.

(15) [...] Para nós, goyannos, o problema da viação é a premissa essencial de qualquer melhoramento e progresso. O nosso maior estorvo econômico é essa desalentadora distancia, que, nas circumstancias actuaes, impede aos nossos productos de poderem concorrer vantajosamente nos mercados do litoral com os produtos similares das outras provincias mais proximas á elle. [...] (Trecho extraído do Jornal A Tribuna Livre, 1878, grifos nossos).

(16)Nós, os que mourejamos no reducto de Justiça e moralidade da VOZ DO POVO faremos de nossa fraqueza força para verberar quaesquer attentados contra a preciosa existencia de S. Excia., pois a nossa razão de ser está precisamos em nos oppormos com vehemencia aos processos alias muito communs ao Caiadismo. Basta de fitas. (Trecho extraído do Jornal Voz do Povo, 1927, grifos nossos).

Já nos trechos (15) e (16) aparecem outras ocorrências de nós. Em todos, é possível notar o cunho político dos discursos, o vocabulário rebuscado e as referências genéricas em que se contextualizam os usos de nós. 
v. 9 (3) 96-114 set-dez 2019
O pronome-sujeito em (15) se substituído por a gente retoma a característica nominal de gente, incluindo seu núcleo feminino (como citado por NEVES, 2012). Assim sendo, se se optar pela sua substituição, tem-se o seguinte: "Para a gente goyanna o problema da viação é a premissa essencial de qualquer melhoramento e progresso." Ou seja, durante a substituição o traço genérico é reafirmado e torna-se sinônimo de "as pessoas".

O mesmo pode acontecer se houver a substituição de nós por a gente no trecho (16). Assim ficaria: "A gente que moureja no reducto de Justiça e moralidade da VOZ DO POVO fará de nossa fraqueza força [...]". No caso em questão a gente denota "o povo".

Nos casos supracitados, pode-se dizer que as variantes não possuem o mesmo significado, por conseguinte, não possuem o mesmo valor de verdade (LABOV, 1978, 2008).

Abaixo, seguem dois gráficos que representam todas as ocorrências das variantes ora analisadas a partir do presente trabalho.

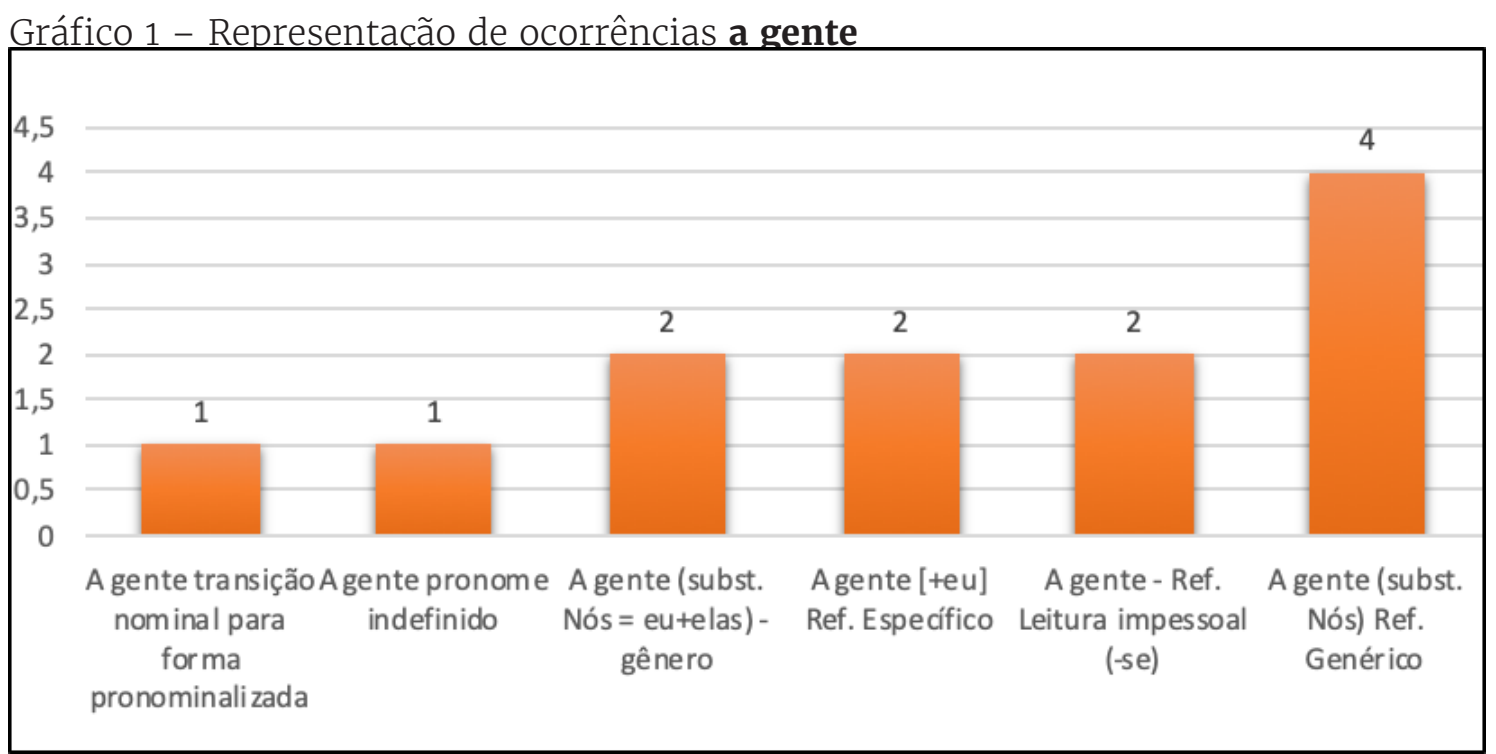

Fonte: dados da pesquisa. 
Gráfico 2 - Representação de ocorrências nós

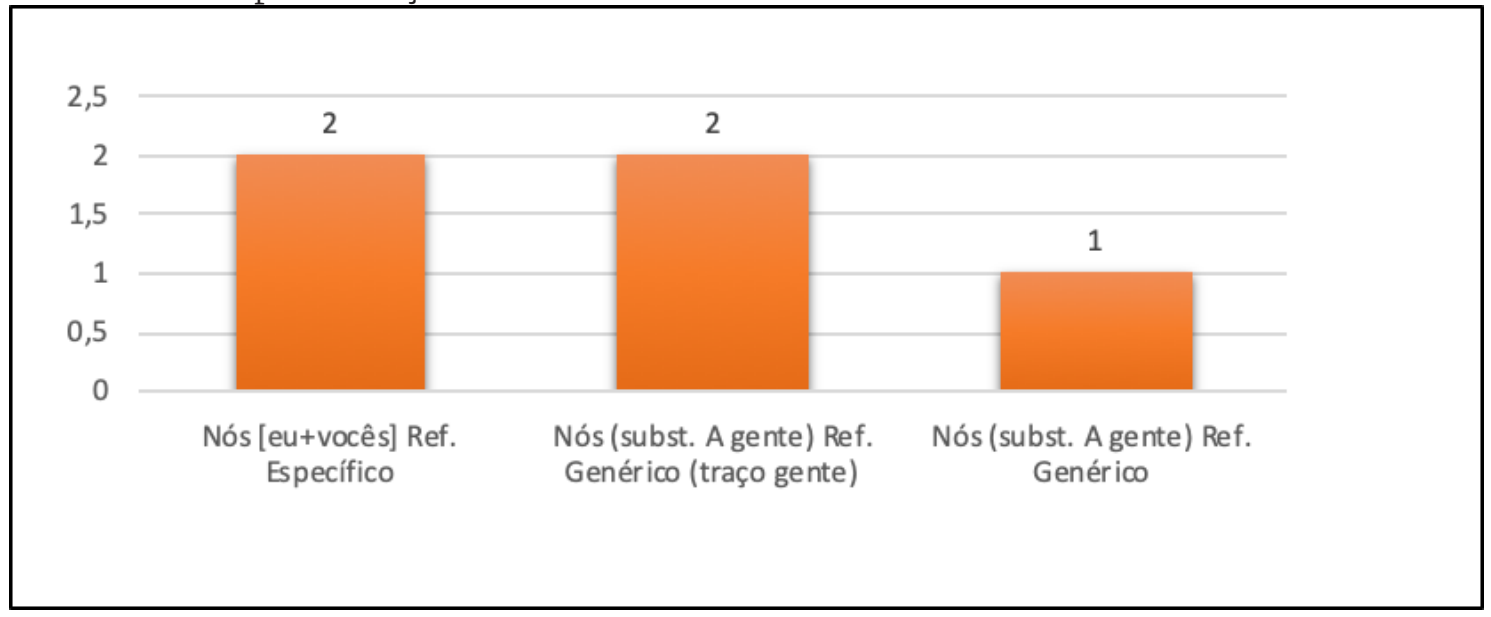

Fonte: dados da pesquisa.

Em ambos os gráficos estão expostos os percentuais de ocorrências de nós e a gente analisadas na presente pesquisa. Retomase a informação de que os dados aqui demonstrados representam apenas uma amostra dos usos verificados nos textos antigos publicados em jornais e periódicos da Cidade de Goiás, cabendo em oportunidade futura a extensão do estudo.

\section{Considerações finais}

Para considerações mais aprofundadas acerca da inserção de a gente na Cidade de Goiás, é necessário que o estudo seja mais bem detalhado, especialmente que sejam buscadas mais ocorrências nos acervos disponíveis.

Importa ressaltar que é perceptível, nos trechos em que figura a gente como forma intercambiável com nós, que o traço semântico característico do substantivo gente não foi de todo perdido durante o processo de gramaticalização.

Dados os estudos anteriormente citados, como explicou Lopes (2003a), esse processo pelo qual a gente passou de nome genérico para pronome indefinido e conseguinte considerado como substituto de nós, tenha viés a partir da interpretação da referida autora de que o pronome nós também pode apresentar conotações diversas, passando por uma possibilidade de determinação do referente [eu + você] até sua indeterminação/generalização em um grau avançado [eu + todo mundo], por exemplo.

No contexto dos excertos aqui apresentados, essa intercambialidade das formas variantes está evidenciada, assim como é possível notar em (10), (11), (12) e (13). Nos trechos citados, a 
V. 9 (3) 96-114 set-dez 2019

intercambialidade pode ser realizada a partir da flexão do verbo adaptada à forma escolhida, sem que haja o prejuízo do sentido original. Inclusive na retomada dos trechos, o caráter genérico (de ambas as formas) que pode aparecer, a depender dos contextos de fala, podem ser percebidos.

Cabe ainda dizer que, ao que parece, a gente (como substituto de nós) deveria ser um uso corrente na fala dos moradores da cidade, já que se revela até na escrita, inclusive figurando nos textos menos formais, como se percebe na análise. Já a preferência por nós dá-se, em maior parte das vezes, em contextos de fala mais formal, como foi possível notar nos trechos de discursos transcritos, que trataram principalmente das questões políticas da época.

Os textos, mesmo sendo em jornais de circulação, reforçam essa hipótese, já que os gêneros textuais em que se encontram as ocorrências de a gente são mais diretamente vinculados a situações menos formais, tais como textos poéticos, reflexões e até num contexto mais satírico, como ocorreu em Matutadas.

Nos discursos publicados eem notícias, por exemplo, predomina o uso do nós. Verifica-se nos excertos um discurso mais voltado às discussões políticas ocorridas nas rodas de classe mais abastadas da cidade. Outro indício é a linguagem mais rebuscada, considerando que esse público mais "elitista" teria maior acesso às literaturas, o que por conseguinte os tornaria mais "cultos".

Ainda é preciso afirmar, que dadas as buscas, foi possível compreender que a inserção de a gente (forma pronominal alternativa a nós) na fala vilaboense deu-se já pelos anos 1800. É possível que, antes de tal data, essa forma estivesse presente na fala da comunidade. Contudo, dada a época, os registros escritos são mais escassos. Apenas a partir do surgimento de jornais na cidade foi possível detectar esses registros.

\section{Referências}

A CRUZ: Revista Catholica, Goyaz, 1890, 29. ed., p. 238. Disponível em: http:// memoria.bn.br/DocReader/DocReader.aspx?bib=763403. Acesso em: 10 dez. 2018.

ÁLBAN, Maria del Rosário; FREITAS, Judith. Nós ou a gente? Estudos linguísticos e literários, Salvador, n. 11, p. 75-89, 1991.

A TRIBUNA LIVRE: Órgão do Club Liberal de Goyaz, Goyaz, 27. ed., 1878. Disponível em: http://memoria.bn.br/DocReader/DocReader.aspx?bib=717592. Acesso em: 10 dez. 2018.

CASTILHO, Ataliba T. de. A gramaticalização. Estudos linguísticos e literários, Salvador, UFBA, n. 19, p. 25-64, 1997. 
CASTILHO, Ataliba T. de. Nova gramática do português brasileiro. São Paulo: Contexto, 2016.

CORREIO OFFICIAL DE GOYAZ, Goyaz, 34. ed., 1880. Disponível em: http://memoria.bn.br/DocReader/DocReader. aspx?bib=167487\&PagFis=177\&Pesq=a\%20gente. Acesso em: 6 jan. 2019.

FREIRE, Isabela. Jornal 0 Lar e a escrita de mulheres em Goiás: o entre-lugar das negociações e reiterações com o poder patriarcal. Dissertação (Mestrado) Universidade Federal de Goiás, Faculdade de Ciências Sociais (FCS) - Programa de Pós-Graduação em Antropologia Social, Goiânia, 2006.

GONCALVES, Sebastião Carlos Leite; LIMA-HERNANDES, Maria Célia; CASSEBGALVÃO, Vânia Cristina. (Org.). Introdução à gramaticalização: princípios teóricos e aplicação. São Paulo: Parábola, 2007.

HOPPER, Paul. J. On some principles of grammaticization. In: TRAUGOTT, E. C. \& HEINE, B. (ed.). Approaches to grammaticalization. Amsterdam/ Philadelphia: John Benjamins Company, 1991.

ILARI, Rodolfo; BASSO, Renato. O português da gente: a língua que estudamos a língua que falamos. 2. ed. São Paulo: Contexto, 2017.

JORNAL CIDADE DE GOIAZ, Goyaz, 70. ed., p. 1, 1940. Disponível em: http:// memoria.bn.br/DocReader/DocReader.aspx?bib=800139x. Acesso em: 10 dez. 2018.

JORNAL GOYAZ, Goyaz, 8. ed., p. 2, 1885. Disponível em: http://memoria. bn.br/DocReader/docreader.aspx?bib=246590\&pasta=ano\%20188\&pesq=. Acesso em: 10 dez. 2018.

LABOV, William. Where does the linguistic variable stop? A response to Beatriz Lavandera. Working papers in sociolinguistics, Washington-DC, n. 44, 1978. Disponível em: https://files.eric.ed.gov/fulltext/ED157378.pdf. Acesso em: 10 mai. 2019.

LABOV, William. Padrões Sociolinguísticos. Trad. Marcos Bagno e Maria Marta Pereira Scherre e Caroline R. Cardoso. São Paulo: Parábola Editorial, 2008.

LAVANDERA, Beatriz R. Los limites de la variable sociolinguística. In: LAVANDERA, Beatriz R. Variación y significado. Buenos Aires: Libreria Hachette, 1984.

LOPES, Célia Regina dos Santos. Nós e a gente no português falado culto do Brasil. DELTA, São Paulo, v. 14, n. 2, 1998. Disponível em: http://dx.doi. org/10.1590/S0102-44501998000200006. Acesso em: 4 set. 2018.

LOPES, Célia Regina dos Santos. A inserção de 'a gente' no quadro pronominal do português. Frankfurt am Main/Madrid: Vervuert/Iberoamericana, 2003a. Disponível em: www.ibero-americana.net/cgi-in/infodetail. cgi?isbn=9788484890614\&doknr=521061\&lang=de\&txt=beschreibung. Acesso em: 15 jul. 2018.

LOPES, Célia Regina dos Santos. A indeterminação no Português arcaico e a pronominalização de nominais: mudança encaixada? ENCONTRO INTERNACIONAL DE ESTUDOS MEDIEVAIS DA ABREM, 5., 2003b. Anais [...]. Salvador: ABREM, 2003b. Disponível em: www.letras.ufrj.br/posverna/ docentes/70994-2.pdf. Acesso em: 30 ago. 2018. 
v. 9 (3) 96-114 set-dez 2019

LOPES, Célia Regina dos Santos. A Gramaticalização de a gente em Português em tempo real de longa e de curta duração: retenção e mudança na especificação dos traços intrínsecos. Fórum Linguístico, Florianópolis, v. 4, n. 1, p. 47-80, jul. 2004. Disponível em: https://periodicos.ufsc.br/index.php/forum/article/ view/7728. Acesso em: 08 ago. 2018.

LOPES, Célia Regina dos Santos. Pronomes pessoais. In: BRANDÃO, Silvia Figueiredo; VIEIRA, Silvia Rodrigues. (org.). Ensino de gramática: descrição e uso. São Paulo: Contexto, 2007, p. 103-114.

NEVES, Maria Helena de Moura. Guia de usos do português: confrontando regras e usos. 2. ed. São Paulo: Editora da UNESP, 2012.

O ESTADO DE GOIAZ, Goiás, 1563. ed., 1955. Disponível em: http://memoria. bn.br/DocReader/DocReader.aspx?bib=763500. Acesso em: 10 dez. 2018.

O PUBLICADOR GOYANO, Goyaz, 45. ed., p. 4, 1886. Disponível em: http:// memoria.bn.br/DocReader/DocReader.aspx?bib=716774. Acesso em: 10 dez. 2018.

PAIVA, Maria da Conceição A. de.; DUARTE, Maria Eugênia Lamoglia. Quarenta anos depois: a herança de um programa na Sociolinguística brasileira. In: WEINREICH, Uriel; LABOV, William; HERZOG, Marvin I. Fundamentos empíricos para uma teoria da mudança linguística. Tradução Marcos Bagno. São Paulo: Parábola, 2006.

PASSADO! PRESENTE... FUTURO?, Voz do povo, Goyaz, 209. ed., 1934. Disponível em: http://memoria.bn.br/DocReader/DocReader.aspx?bib=763454. Acesso em: 10 dez. 2018.

VIANNA, Juliana Segadas; LOPES, Célia Regina dos Santos. Variação dos pronomes "nós" e "a gente". In: ABRAÇADO, Jussara; MARTINS, Marco Antonio. (Org.). Mapeamento sociolinguístico do português brasileiro. São Paulo: Contexto, 2015. p. 109-131.

VOZ Do POV0, Goyaz, 3. Ed., 1927. Disponível em: http://memoria.bn.br/ DocReader/DocReader.aspx?bib=763454\&PagFis $=4 \&$ Pesq =n\%C3\%B3s. Acesso em: 10 dez. 2018.

VOz DO Povo. Goyaz, 6. ed., p. 4, 1927. Disponível em: http://memoria. bn.br/DocReader/DocReader.aspx?bib=763454. Acesso em: 10 dez. 2018.

VOZ DO POVo. Goyaz, 8. ed., p. 4, 1927. Disponível em: http://memoria.bn.br/ DocReader/DocReader.aspx?bib=763454. Acesso em: 10 dez. 2018.

WEINER, E. Judith; LABOV, William. Constraints on the agentless passive. Journal of linguistics, Cambrigde, n. 19, p. 29-58, 1983. Disponivel em: http://journals. cambridge.org/abstract_So022226700007441. Acesso em: 10 mai. 2019.

WEINREICH, Uriel; LABOV, William; HERZOG, Marvin I. Fundamentos empíricos para uma teoria da mudança linguística. Tradução Marcos Bagno. São Paulo: Parábola, 2006. 